\title{
The Increasing Prevalence of Haemophilia
}

Dear Sir,

Treatment of haemophilıa patients depends on an adequate supply of blood products As long as clotting factor preparations produced by recombinant DNA techniques are not widely avallable, changes in the number of patients may threaten the precious balance of blood donations and plasma products consumption

The observed prevalence of haemophilia is the resultant of the prevalence at burth and mortality It may be affected by genetic counseling of carrier women and selective abortion and also by the fertility of patients Until only 20 years ago haemophilia patients had a life expectancy less than 30 years (1), and therefore the prevalence we observe today will be much smaller than the prevalence at birth Nowadays, life expectancy is only mildly reduced (2), aside from the present AIDS mortality which differs from country to country The present longevity of haemophilia patients will therefore lead to an increase in their number

This is illustrated in Fig 1, which shows the prevalence of haemophilia per age group in The Netherlands These data were obtained by a survey of all registered 1,162 Dutch haemophilia patients Information was avalable for $80 \%$ of the patients, the prevalence date have been extended to all 1,162 In each age group the number of patients in divided by the total number of men in The Netherlands of that age (3) Up to age 20 (mid interval) the prevalence increases This is likely to be caused by delays in diagnosis, manly of mild haemophilia After age 40 (mid interval), there is a steady decline of the age specific prevalence This deficit of older patients can only be explained by excess mortality in the past The plateau of 206 per 100,000 males approxumates the prevalence at birth If this prevalence were present at all ages, the number of haemophilia patients would be almost $1,500,1 \mathrm{e} 28 \%$ more than the present number of haemophilia patients in The Netherlands

At the moment the mortality in haemophilia is twice as high as in the general population, aside from AIDS mortality This leads, as calculated by life table method, to a reduction in the overall prevalence of about $10 \%$ Prenatal diagnosis and selective abortion might affect the prevalence at birth, this effect will be minimal however, since we found in a recent survey of 549 female relatives of haemophlia patients that only a minority of carriers choose for this option (4), which corroborates reports from the United Kingdom (5) Furthermore, we noted that the younger patients were relatively more often married than the older patients Haemophilia patients had on average less children than men in the general population, which was partly caused by their being less often married, and partly by genetic and physical considerations The improved physical condition of haemophilia patients is therefore likely to lead to an increase in the number of carrier daughters of haemophilia patients, and in two generations this will cause a further increase in the prevalence at birth

The number of HIV positive haemophilia patients and the ensuing mortality differ widely from one country to another In The Netherlands the number of infected patients is relatively low (less than 20\%) (6), and therefore the rise in the number of patients will occur in one generation In countries in which the majority of patients is HIV positive, excess mortality may at first lower the prevalence, but this will be a temporary effect The attitude towards prenatal diagnosis may also be different in other countries Nevertheless, we think that the substantial growth in

Correspondence to F R Rosendaal, Dept of Clinical Eprdemiology, Bldg 1, C0 P 46, University Hospital Leiden, P O Box 9600, 2300 RC Lerden, The Netherlands

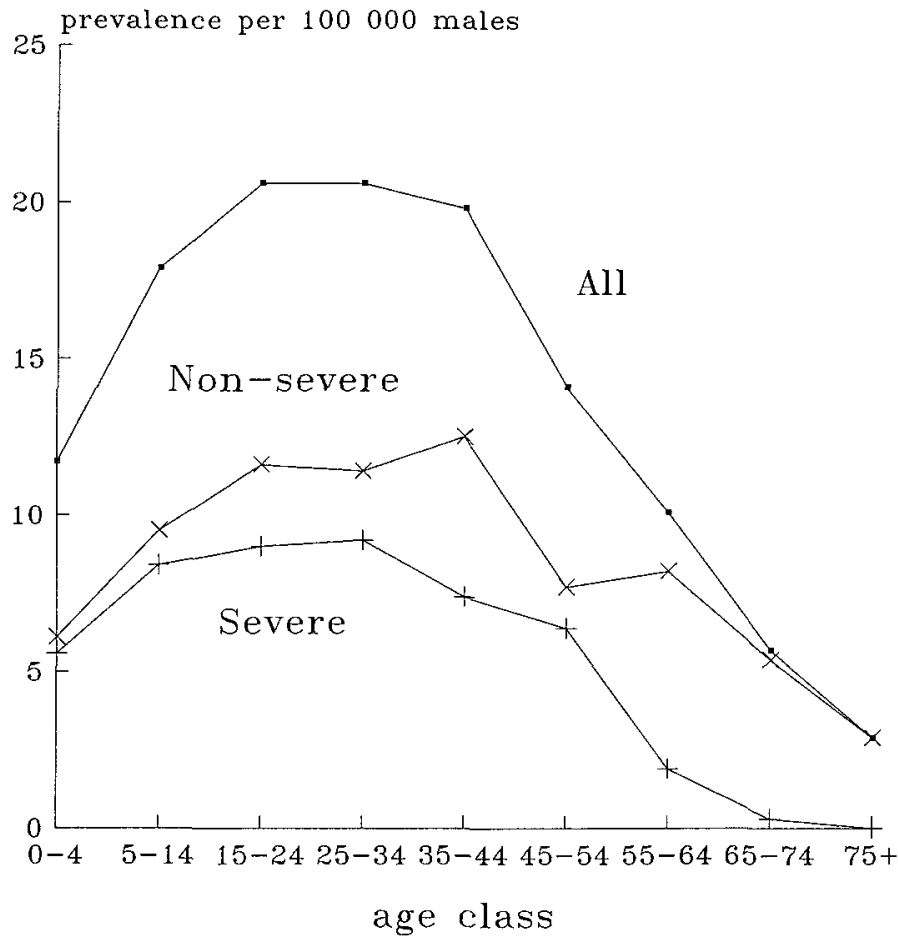

Fig 1 Prevalence of haemophilıa by age For each age group the number of haemophilia patients, corrected for non response, is related to the number of individuals in that age group in the general male population

the number of haemophiliacs by about $20 \%$ we foresee in The Netherlands is likely to occur in many Western countries The "extra" patients will be mostly those with severe hemophilia, since they showed the largest deficit in the older age groups because of excess mortality in the past

\section{F R Rosendaal}

E Briet ${ }^{2}$

1 Department of Clinical Epidemiology

${ }^{2}$ Department of Haematology

University Hospital Leiden, The Netherlands

\section{References}

1 Larsson S A Life expectancy of Swedish haemophiliacs, 1831-1980 Br J Haematol 1985, 59 593-602

2 Rosendaal F R Varekamp I, Smit C, Brocker-Vriends A, Van Dijck H, Vandenbroucke J P, Hermans J, Suurmeıjer T P B M, Briet E Mortality and causes of death in Dutch haemophiliacs, 1973-1986 $\mathrm{Br} \mathbf{J}$ Haematol 1989, 71 71-6

3 Central Bureau of Statıstıcs Statıstical Yearbook 1985 Staat suitgeverij, Den Haag 1986

4 Varekamp I, Rosendaal F R, Smıt C, Brocker-Vrıends A, Van Dijck H, Briet E, Suurmeijer T P B M Carrier testıng and prenatal diagnosis for hemophilia experiences and attıtudes of 549 potential and obligate carriers Am J Med Genet 1989 (1n press)

5 Markova I, Forbes C D, Inwood M The consumers' view of genetic counseling of hemophilia Am J Med Genet 1984, 17 741-52

6 Rosendaal F R, Smıt C, Varekamp I, Brocker-Vrıends A, Suurmeijer T P B M, Biret E AIDS and haemophilia a study among Dutch haemophiliacs on the psychological impact of the AIDS threat, the prevalence of HIV antibodies and the adoption of measures to prevent HIV transmission Haemostasıs 1988, 18 73-82

Reccrved October 6, 1989 Accepted October 27, 1989 